\title{
The New Discovery of Three Skulls of Sinanthropus pekinensis
}

\author{
By Dr. Franz Weidenreich, \\ Visiting Professor of Anatomy, Peiping Union Medical College, and Honorary \\ Director of the Cenozoic Research Laboratory, National Geological Survey of China
}

FOLLOWING the recovery of several fragments of a very small adult skull of Sinanthropus from Locus I (Locality 1) in the latter part of our spring field season at Choukoutien, we had the good fortune during the fall season of this year to unearth three additional more or less well-preserved skulls, two of which were recovered on one day. All three skulls belong to adult individuals. The skull recovered first, and designated as Skull I of Locus L (Fig. 1), is the largest, with a cranial capacity of approximately 1,200 c.c. and with its coronal and sagittal sutures partly fused. The second skull (Skull II of Locus L, Fig. 2) is the smallest of the group, with a cranial capacity not higher than 1,050 c.c., and its coronal, sagittal and lambdoid sutures fused. This skull shows a clear indication of the persistence of a metopic suture. The third skull (Skull III of Locus L, Fig. 3) is smaller than Skull I, but larger than Skull II. The cranial capacity of Skull III is approximately 1,100 c.c. Although all the sutures of this skull are still patent, yet other characteristic features make it evident that we are concerned with a young adult individual. Parts of the face are preserved in all three skulls; thus, in Skull III both nasal bones and the entire lateral border of the orbit in

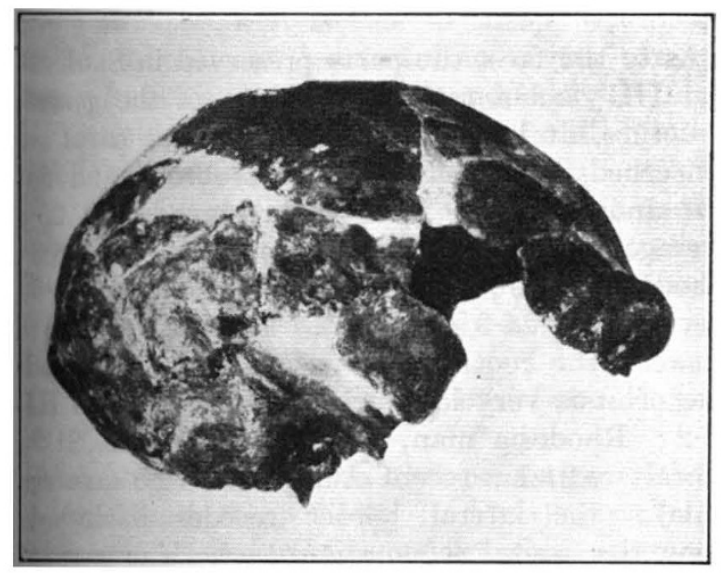

Fig. 1.

Sinanthropus pekinensis, SkULL I, Locus L, ADUlt Male. Norma lateralis, RIGHT SIDE. $\times \frac{1}{3}$.

complete connexion with the brain case ; in Skull II the frontal process of the maxilla, the lower border of the orbit, the cheek-bone and fragments of the alveolar process of the upper jaw with palate and ten teeth in situ (premolars and molars), which, however, are not connected with the skull. Belonging to Skull I are several teeth only. In addition, we have a great number

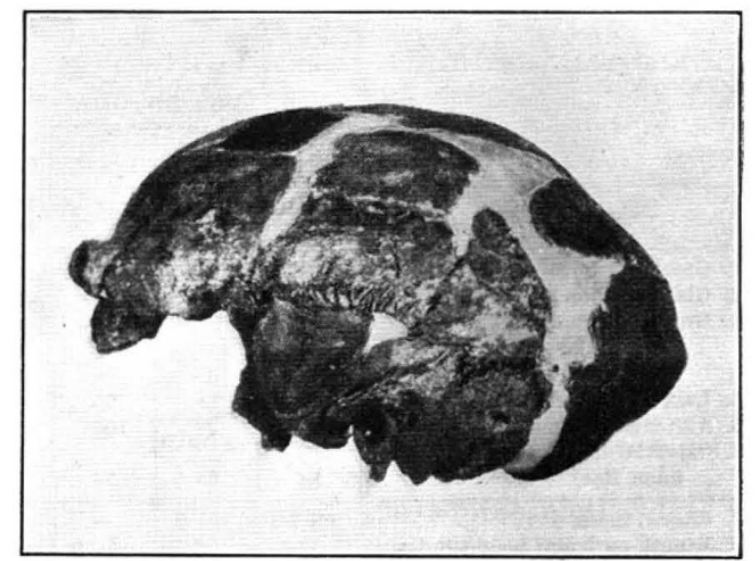

Fig. 2.

Sinanthropus pekinensis, SkULI II, Locus I, ADULT female. Norma rateralis, Left side. $\times \frac{1}{3}$.

of very small fragments apparently pertaining to the face, yet it is rather doubtful whether it will be possible to undertake even a partial reconstruction.

As has been noted in the case of all teeth of Sinanthropus recovered hitherto, it is also true for Sinanthropus Skulls I and II, namely, that they possess a large and a small type of teeth. I had previously arrived at the conclusion that the large teeth may belong to male individuals and the small to female individuals. This assumption has been confirmed by the fact that the large type of teeth pertain to the bigger skull (Skull I) while the small type of teeth is to be found in the small skull (Skull II, Fig. 4). Thus it seems quite certain that the latter represents the skull of a female individual, and the former that of a male individual.

Parts of the base are missing in all three skulls. Skull $\mathrm{I}$ is the most defective, with only the right temporal bone being preserved. In Skull II both temporal bones are present, but a great part of the supraorbital region is broken off. Skull III is the most complete one ; the entire occipital bone with the posterior border of the foramen magnum is preserved. However, the right temporal bone has been lost. 
All three skulls have the same appearance as Skull I of Locus $\mathrm{E}$ described by Davidson Black (1931). However, since this skull belongs to a child of eight-nine years (cf. Weidenreich, 1935), the characteristics of the Sinanthropus type are much more pronounced in the recently recovered skulls such as, for example, the size and thickness of the supraorbital ridges and the occipital torus, the crest of the vertex and the muscle markings of the temporal bone. The greatest transversal diameter of all three skulls is represented by the biauricular breadth with the breadth decreasing gradually above the ear aperture. The accompanying table (see below) shows the results derived
Since the character of a type is not always defined by the general shape only but also by the feature of details, it deserves special attention here that the new Sinanthropus skulls completely agree. with Skull $\mathrm{I}$ of Locus $\mathrm{E}$ in this respect. This is true, for example, in respect to the position and form of the ear aperture-with the exception of the cleft of the tympanic part of the temporal bone which is distinctly an infantile eharacter in recent man and is missing in all adult Sinan. thropus skulls--and in regard to the smallness and form of the mastoid process, as also the very narrow space between the temporal lines on both sides.

TABLE*

\begin{tabular}{|c|c|c|c|c|c|c|c|c|c|c|c|}
\hline & \multicolumn{4}{|c|}{ Sinanthropus } & \multirow{2}{*}{$\begin{array}{c}\text { Pithe- } \\
\text { can- } \\
\text { thropus }\end{array}$} & \multicolumn{4}{|c|}{ Neanderthal group } & \multirow[b]{2}{*}{$\begin{array}{c}\text { Recent } \\
\operatorname{man}^{3}\end{array}$} & \multirow{2}{*}{$\begin{array}{l}\text { Chim- } \\
\text { pan- } \\
\text { zee }^{3}\end{array}$} \\
\hline & $\begin{array}{c}\text { I } \\
\text { Loc. L }\end{array}$ & $\begin{array}{l}\text { II } \\
\text { Loc. I }\end{array}$ & $\operatorname{IIf}_{\text {Loc. L }}$ & $\begin{array}{c}\mathrm{I} \\
\text { Loc. } \mathrm{E}^{\mathrm{x}}\end{array}$ & & $\begin{array}{c}\text { Nean- } \\
\text { derthal }\end{array}$ & Spy I & $\begin{array}{l}\text { La Cha- } \\
\text { pelle }\end{array}$ & $\begin{array}{l}\text { Rhod- } \\
\text { esia }\end{array}$ & & \\
\hline $\operatorname{Sex}$ & a & 우 & 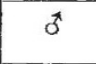 & (chiild) & 우 & $\sigma^{2}$ & o & * & c & $0+q$ & $x+q$ \\
\hline 1. Greatest length (g-op) .. & 198 & 191 & 195 & 188 & 183 & 201 & 203 & 208 & 206 & & \\
\hline 2. Glabello-inion length $(\mathrm{g}-\mathrm{i})$ & 195 & 188 & 194 & 185 & 177 & 199 & 198 & 195 & 204 & & \\
\hline 3. Greatest breadth : & & & & & & & & & & & \\
\hline a. auricular.. & 148 & 145 & 147 & 144 & 140 & - & - & 144 & 142 & & \\
\hline b. temporo-parietal .. & 136 & 137 & - & 133 & 130 & 147 & 147 & 156 & 146 & & \\
\hline 4. Last frontal breadth $\ldots$ & 89 & 88 & 90 & 82 & 85 & 107 & 104 & 109 & 100 & & \\
\hline 5. Auricular-bregmatic height $(p o-b)$ & $107 \cdot 5$ & 98 & 100 & 93 & 94 & $\cdots$ & 118 & 115 & 116 & & \\
\hline $\begin{array}{c}\text { 6. Calvarial height (over glabello- } \\
\text { inion line) } \\
. .\end{array}$ & 84 & $65 \cdot 5$ & 78 & 70 & $66 \cdot 2$ & $80 \cdot 5$ & 81 & 79 & 90 & & \\
\hline 7. Cranial index $\ldots$ & $68 \cdot 7$ & $71 \cdot 8$ & - & $73 \cdot 6$ & $71 \cdot 0$ & $73 \cdot 1$ & $72 \cdot 4$ & $75 \cdot 0$ & $70 \cdot \overline{9}$ & - & $\therefore$ \\
\hline 8. Length-auricular height index. & $53 \cdot 4$ & $50 \cdot 7$ & $51 \cdot 0$ & $50 \cdot 3$ & $51 \cdot 4$ & - & $54 \cdot 7$ & $55 \cdot 4$ & $56 \cdot 3$ & $63 \cdot 8$ & $51 \cdot 2$ \\
\hline 9. Calvarial height index .. & $43 \cdot 1$ & $34 \cdot 8$ & $40-2$ & $37 \cdot 9$ & $37 \cdot 9$ & $40 \cdot 4$ & $40 \cdot 9$ & $40 \cdot 5$ & $45 \cdot 4$ & $59 \cdot 8$ & $32 \cdot 5$ \\
\hline 10. Bregmatic index (Schwalbe) .. & $39 \cdot 5$ & $44 \cdot 2$ & $39 \cdot 2$ & $39 \cdot 5$ & $40 \cdot 9$ & $38 \cdot 4$ & $34 \cdot 5$ & $36 \cdot 5$ & $36 \cdot 4$ & $28 \cdot 0$ & $50 \cdot 0$ \\
\hline 11. Bregmatic angle (Schwalbe) .. & $47^{\circ}$ & $39^{\circ}$ & $44^{\circ}$ & $43^{\circ}$ & $42^{\circ}$ & $44^{\circ}$ & $46^{\circ}$ & $45 \cdot 5^{\circ}$ & $48^{\circ}$ & $59^{\circ}$ & $39^{\circ}$ \\
\hline 12. Superior inion angle (lig) & $74^{\circ}$ & $60^{\circ}$ & $62^{\circ}$ & $64 \cdot 5^{\circ}$ & $70^{\circ}$ & $66 \cdot 5^{\circ}$ & $68^{\circ}$ & $68 \cdot 5^{\circ}$ & $70^{\circ}$ & $84^{\circ}$ & $50^{\circ}$ \\
\hline 13. Inion angle (lio) .. & - & - & $96^{\circ}$ & - & $99^{\circ}$ & $118^{\circ}$ & $122^{\circ}$ & $113^{\circ}$ & $107^{\circ}$ & $119^{\circ}$ & $110^{\circ}$ \\
\hline 14. Capacity (c.c.) .. & c.1200 & $c .1050$ & c. 1100 & 914 & $1000 ?$ & $c .1370$ & - & 1620 & 1325 & 1325 & 410 \\
\hline
\end{tabular}

* The figures in italic type represent limiting values of the individual groups, with the exception of recent man and chimpanzee. Measurements of Locus E skull not considered in limiting values on account of its immaturity.

1 After Davidson Black's flgures, but the position of inion has been rectified. ' 2 Reconstruction after Weinert. 'Average figures of all races.

from the more essential skull measurements in comparison with those available for Pithecanthropus, Neanderthal and recent man. The measurements 8-13 giving the corresponding ratios reveal that Sinanthropus as a whole occupies the lowest place in the order of all hominids in regard to those peculiarities which determine its position in the line of evolution. This is particularly true for Skull II of Locus L, while Skull I of Locus L in part falls within the range of variations of the Neanderthal group. However, Skull II apparently is even lower than Pithecanthropus, the difference being that the Sinanthropus skull shows a more pronounced frontal tuber than Pithecanthropus, the entire forehead of which is flattened. The smallness and lowness of Sinanthropus Skull II is all the more remarkable since the skull fragments recovered last summer and considered to pertain to an adult individual are still smaller in dimensions than the respective parts of Skull II of Locus $\mathrm{L}$ and Pithecanthropus (cf. Weidenreich, 1937).
As to the face, the parts preserved in Skulls II and III yield a rather good idea of the general structure, at least so far as the upper parts are concerned. The nasal bridge is broad and flat (the index of the inter-orbital breadth is 29.8 average); Neanderthal group: Spy I, 28.8; Rhodesia, 28.6 ; La Chapelle aux Saints, 26.8; recent man, $24 \cdot 3$ (average). There is no groove between the root of the nose and the forehead. The orbit is very low (orbital index of Skull III, 77.2 ; Rhodesia man, 75.5; La Chapelle, 81.9; Gibraltar, $91 \cdot 1$; recent Australian, 78.8 (average male); the lateral border recedes backwards below the frontal zygomatic suture. The lacrimal fossa is missing in all skulls. The orbit is deep and the superior orbital fissure very small. The cheek bone is remarkably high, as high as that of the Rhodesia skull. A canine fossa does not exist and the anterior surface of the frontal process of the maxilla is slightly convex and not depressed as in recent man. The upper jaw, therefore, must 
have projected considerably. The palate is broad and high.

Earlier (1935) I was able to demonstrate that a close connexion between Sinanthropus and certain groups of the present Mongol race could be assumed. The occurrence of the so-called 'torus mandibularis' on the inner side of the mandible of some of the Sinanthropus jaws as well as on those of recent Mongols, especially Eskimos and Lapps, and furthermore the occurrence of shovel-shaped medial and lateral upper incisors in Sinanthropus, as also in modern Mongols, indicate some direct relationship between Peking man and the Mongol group of recent mankind. Whether or not the broad and flat nose of Sinanthropus points to the same direction I do as yet not venture to state. However, in addition, there is another conspicuous feature which, I believe, serves as further evidence for the assumption of such a special relationship. All three adult skulls show a large 'inca-bone' (os epactale) which, it is true, is not confined to the ancient Peruvian natives as the name suggests but also occurs in other races of to-day. However, it is much more frequent in the American Indian and Mongol group (up to 7.8 per cent) than in the latter (up to 2 per cent).

One of the most striking features revealed by the recently recovered skulls is met with in the endocranial casts. I had previously remarked (1936) that, in the Sinanthropus Skull of Locus D (Black's Skull II), the pole of the frontal lobe of the brain projects far outward and continues with a sharp keel downward (orbital rostrum). This peculiarity is especially pronounced in Skull III, and in somewhat different manner also in Skulls I and II of Locus $\mathrm{L}$; in the latter two the keel is not so sharp, but nevertheless it projects downward in a very straight line. In this respect the endocast of Skull III resembles that of a chimpanzee, while Skulls I and II resemble more that of a gorilla. At any rate, all endocasts differ distinctly in this respect from those of Neanderthal man or Pithecanthropus. Skulls II and III are furthermore remarkable for the existence of an astonishingly low and narrow temporal lobe, a condition which I had pointed out when describing the temporal bone of Skull III of Locus H (1936 a).

As to the relation to Pithecanthropus, Sinanthropus Skull II of Locus L, together with the fragmentary Sinanthropus of Locus I mentioned above, prove incontestably that there is no appreciable difference between Pithecanthropus and Sinanthropus so far as the general shape and the lowness of the skull caps are concerned. Since it has been assumed that these two Sinanthropus skulls belong to female individuals, it is very probable that Pithecanthropus also belongs to the same sex, a probability which had already been pointed out by E. Dubois and Hrdlička. The Sinanthropus skulls differ from Pithecanthropus by only two characters, namely, in that the frontal bone proper is more vaulted in Sinanthropus, although its inclination to the glabella-inion line is distinctly more pronounced than in Pithecanthropus (compare measurements 10 and 11 of

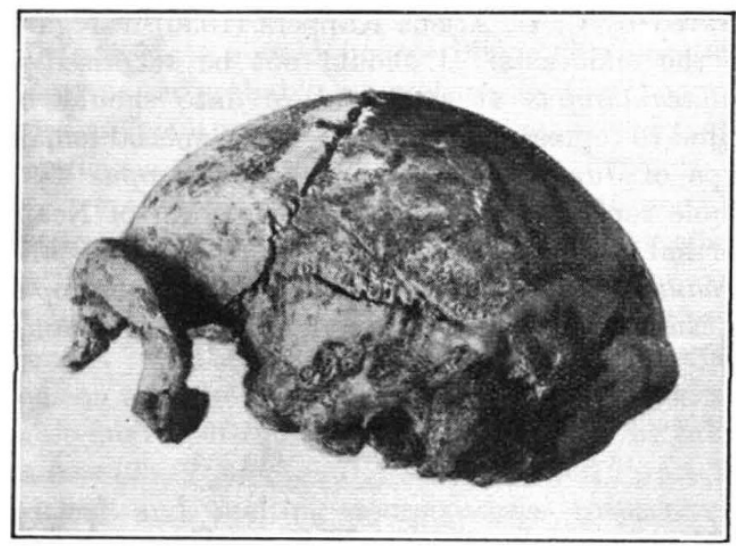

Fig. 3.

Sinanthropus pekinensis, SkULL III, LocUs L, ADULT male (YoUNG). Norma lateralis, left side. $\times \frac{1}{3}$.

table). Furthermore, the supraorbital ridges of Sinanthropus are separated from the forehead by a really broad furrow, while in Pithecanthropus they continue gradually to the brow. The latter phenomenon, however, seems to have some connexion with the formation of the frontal airsinuses. In Pithecanthropus these sinuses are conspicuously large and extend far lateralward over the roof of the orbit, whereas in all cases in Sinanthropus they are very small and closely confined to the interorbital region. I consider this appearance in the case of Sinanthropus as an indication of its being more primitive than Pithecanthropus, and the latter, in spite of the absence of prominent frontal tubera, as a more ad. vanced type of hominid.
Fig. 4.

UPPER CANINES AND UPPER FIRST PREMOLARS OF MALE SkUll I and female SkULI II. $\times \frac{1}{2}$. FROM LEFT TO RIGHT: CANINE, SKULI I, CANINE, SKULL

II; PREMOLAR, SKULI I, PREMOLAR, SKULL II.

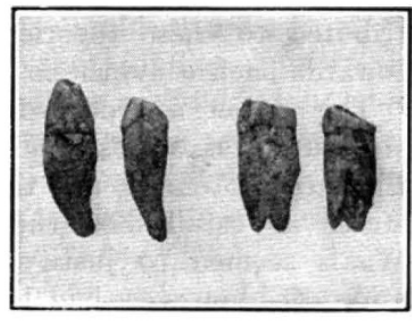

Another important fact is disclosed by Sinanthropus Skull I of Locus L. This skull is not only the largest of all Sinanthropus skulls recovered hitherto (c. 1,200 c.c.) but at the same time also the highest. Although its general structure and essential details show the same characters as the lowest Skull II of Locus L, yet its greater cranial 
capacity approaches closely the more primitive representatives of the Neanderthal group as revealed by the table. I had earlier (1936 b) assumed that there must be some relation between Pithecanthropus and Javanthropus soloensis, the latter resembling the former in several primitive characters. On the other hand, there is no doubt that Javanthropus has many peculiarities in common with Sinanthropus, as recently demonstrated by C. U. Ariëns Kappers (1936) in regard to the endocasts. I should not be surprised if Pithecanthropus at some future date should be found to represent nothing else but a special female type of Javanthropus. Since Javanthropus as a whole represents a very primitive form of Nean- derthal man, the line linking Pithecanthropus and Sinanthropus, respectively through Javanthropus or Neanderthal man, to recent man is continuous.
The fact that there may be certain racial deviations does not matter greatly, since the determining factor does not depend on relatively minute differences but on the main course of human development itself.

\section{IITERATURE.}

Black, Davidson (1931). “On an Adolescent Skull of Sinanthropu pekinensis in Comparison with an Adult of the Same Species and with Other Hominid Skulls Recent and Fossil". Palcontologia Sinica, Ser. $\mathrm{D}, 7$, Fasc. 2 .

Kappers, C. U. Ariëns (1936). "The Endocranial Casts of the Fhringsdorf and Homo soloensis Skulls". J. Anat., 71, 61-76.

Weidenreich, Franz (1935). "The Sinanthropus Population of Weidenreich, Franz (1935). "The Sinanthropus Population of Choukoutien (Locality 1) with a Preliminary Roport
coveries". Bull. Geol. Soc. China, 14, No. 4, 427-468.

Weidenreich, Franz (1936a). "Observations on the Form and Proportions of the Endocranial Casts of Sinanthropus pekinensis, Other Hominids and the Great Apes: a Comparative Study of Brain Size". Paloontologia Sinica, Ser. D, 7 , Jasc. 4.

Weidenreich, Franz (1936b). "Sinanthropus pekinensis and its Position in the Line of Human Evolution". Bull. Peking Nat. Hist., 10, Pt. 4, 281-290.

Weidenreich, Franz (1937). "The New Discoveries of Sinanthropus pekinensis and their Bearing on the Sinanthropus and Pithecanthropus pekinensis and their Bearing on the Sinanthropus and Pithecant
Problems". Bull. Geol. Soc. China, Ting Memorial Volume.

\section{The Structure of Liquids}

$\mathrm{T}$ HE Edinburgh discussion of the Faraday Society on September 24-26 on the subject of "The Structure of Liquids and Solutions" was a particularly successful and satisfactory conference. The choice of subject had been very happily timed. The theory of the structure of liquids, which has been in recent years approached from a number of different angles, appears now to have reached a stage in which a larger synthesis is possible, and the bringing together in Edinburgh of many of those who have most notably contributed to these theories has markedly helped towards such a synthesis.

The earlier approach to the theory of liquid structure was almost inevitably an extension of the theory of gases, and the continuity of the two states as established theoretically by Van der Waals seemed to justify this treatment. This approach, however, had led to but little advance in explaining most of the characteristic properties of liquids. A recent tendency, on the other hand, which has taken its origin in the X-ray studies of liquid structure, has been to treat the liquid as more closely analogous to the crystalline solid. This has proved a much more fruitful line of advance for ordinary liquids, that is for liquids at temperatures far removed from their critical temperatures.

The chief difference between liquids and crystals is that in liquids we have irregularity of position and orientation of molecules in the place of the regularity of the crystal. arrangement. This irregularity is limited by the general condition that in liquids the molecules are approximately close-packed. A great advance in the study of liquids is the development of the precise method of defining the molecular or atomic configuration of a liquid under any conditions. This has been achieved by means of the distribution function $g(r)$ of Debye and Prins, which gives the probability

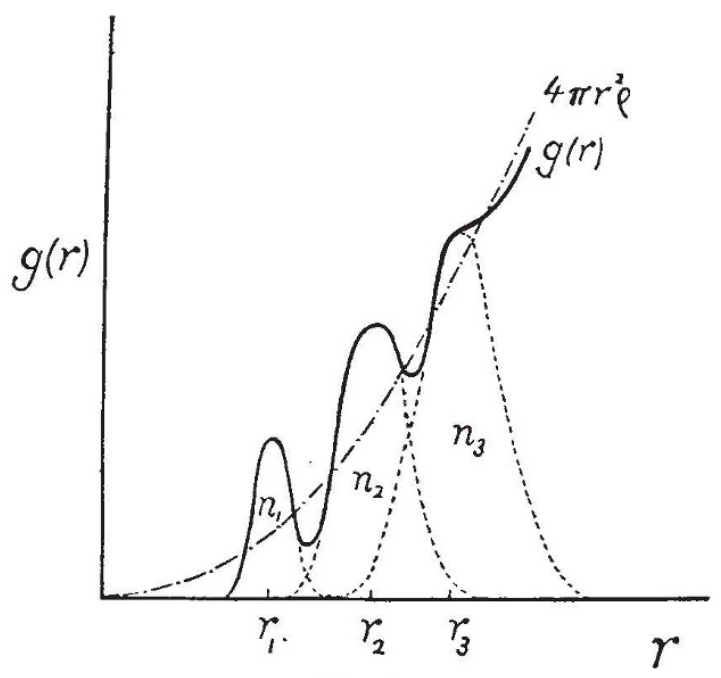

Fig. 1.

of finding a molecule at every distance from an arbitrarily chosen one (see Fig. 1). The peaks of the distribution function correspond to the perfect coordination spheres surrounding atoms in a regular crystal structure, and Prins has suggested that one can be derived from the other by considering each co-ordination sphere of mean radius $r_{k}$ and 